\title{
Discussion
}

on paper published in

Advances in Cement Research

1994, 6, No. 22, Apr., 67-72

\section{Neutron radiography: an excellent method of measuring water penetration and moisture distribution in cementitious materials}

\author{
H. Justnes, K. Bryhn-Ingebrigtsen and G. O. Rosvold \\ Contribution by W. D. Hoff and M. A. Wilson \\ Department of Building Engineering, UMIST, PO Box 88, Manchester M60 IQD, UK
}

The paper by Justnes et al. provides a good illustration of the use of neutron radiography as a method of measuring water distribution in cementitious materials. The results they have given are very interesting and can be analysed further.

The absorption of water by porous inorganic construction materials and the movement of water within them can be described by using concepts of unsaturated flow that were first developed in soil physics. ${ }^{1}$ This approach is now well established and is being adopted increasingly. ${ }^{2}$

Using this analysis it can be shown that one-dimensional horizontal flow is described by the non-linear diffusion equation

$$
\frac{\partial \theta}{\partial t}=\frac{\partial}{\partial x}\left(D(\theta) \frac{\partial \theta}{\partial x}\right)
$$

where $\theta$ is the water content and $D(\theta)$ is the unsaturated hydraulic diffusivity, a property of the porous material. The solution of this equation has the form

$$
x(\theta, t)=\phi(\theta) t^{1 / 2}
$$

The total amount of water absorbed is then given by

$$
i(t)=t^{1 / 2} \int \phi \mathrm{d} \theta=S t^{1 / 2}
$$

where $S$ is the sorptivity. The use of sorptivity as a measure of the capillary absorption properties of porous construction materials is now widespread. ${ }^{3,4}$

Equation (3) suggests that the amount of water absorbed (and therefore the advance of the wet front in a material of constant porosity) will vary linearly with the square root of time. More specifically, equation (2) predicts that a $t^{1 / 2}$ relationship is true not only for the advance of a more or less sharp wetting front but generally for any point on the penetrating water content profile.

Gummerson et al. ${ }^{5}$ have used nuclear magnetic resonance imaging to monitor the absorption of water into a range of porous inorganic solids, and their results confirm that the water content-distance profiles collapse onto a master curve when the water content is plotted against $x t^{-1 / 2}$. Carpenter $e t$ al. ${ }^{6}$ have obtained similar results for capillary water migration in limestone using this technique.

The data reported by Justnes et al. for their mortar samples would therefore be expected to give results consistent with this theoretical analysis. The fact that their experiments used a vertical rather than a horizontal absorption geometry would not be expected to invalidate the application of the analysis, because the mortar materials used are so fine-pored that gravitational effects on the absorption process are negligible over the heights of rise measured. In Fig. 1 their data are plotted to show the advance of the wet front against the square root of time. The results suggest that the data do not form a consistent set, because the $24 \mathrm{~h}$ and $48 \mathrm{~h}$ absorptions show a smaller advance than would be predicted from the $2.5 \mathrm{~h}$ and $4 \mathrm{~h}$ results. It is significant that two different specimens have been used in this work, one for the $2.5 \mathrm{~h}$ and $4 \mathrm{~h}$ measurements and the other for the $24 \mathrm{~h}$ and $48 \mathrm{~h}$ measurements. Although the two specimens were of the same nominal composition it is possible for slight 


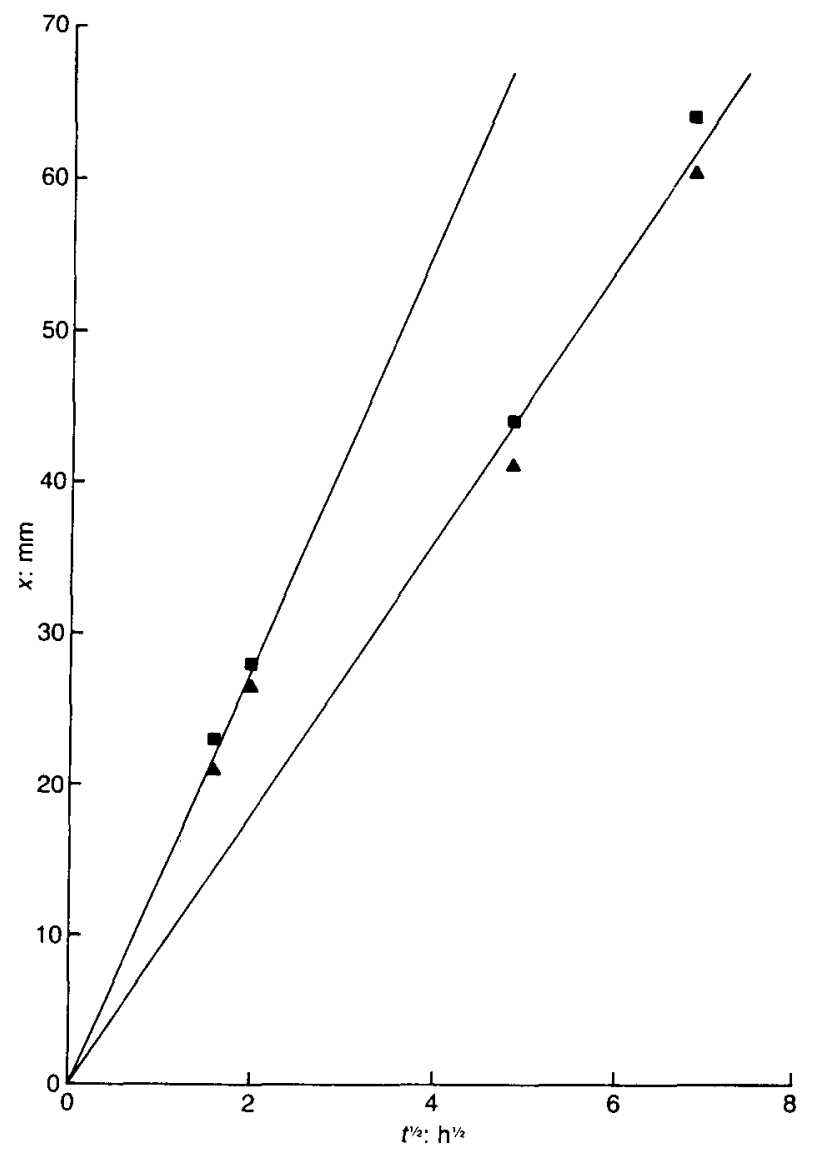

Fig. 1. Graphs showing the advance $x$ of the wet front in the mortar specimens of Justnes et al.: the two straight lines are from different specimens; the data points shown by squares are the visually determined heights of rise and the data points shown by triangles are the heights of rise determined by image analysis

differences in compaction during casting to produce significant differences in absorption characteristics.

Figure 2 shows the results of replotting the three profiles shown in Fig. 4 of the paper by Justnes $e t$ al. It is significant that when the intensity profiles are replotted against $x t^{-1 / 2}$ the results for the $2.5 \mathrm{~h}$ and $4 \mathrm{~h}$ profiles approximately coincide, but the $24 \mathrm{~h}$ results form a separate set. This is presumably due to the $24 \mathrm{~h}$ profile being obtained from a different specimen. Smoothing the data plotted in Fig. 2, it is possible to calculate the unsaturated hydraulic diffusivity $D(\theta)$ of the mortar using the method of Bruce and Klute. ${ }^{7}$

The diffusivity function $D(\theta)$ for soils and for construction materials is found to be an approximately exponential function of the reduced water content $\theta_{\mathrm{r}}$, so that

$$
D=D_{0} \exp \left(B \theta_{\mathrm{r}}\right)
$$

where $B$ normally lies in the range $4-9 .{ }^{8}$ The diffusivity functions for the two mortars are shown in Figs 3 and 4 , from which it is clear that for these materials $B \approx 4$.

In conclusion, analysis of the data from the paper by Justnes $e$ al. provides further useful confirmation of the

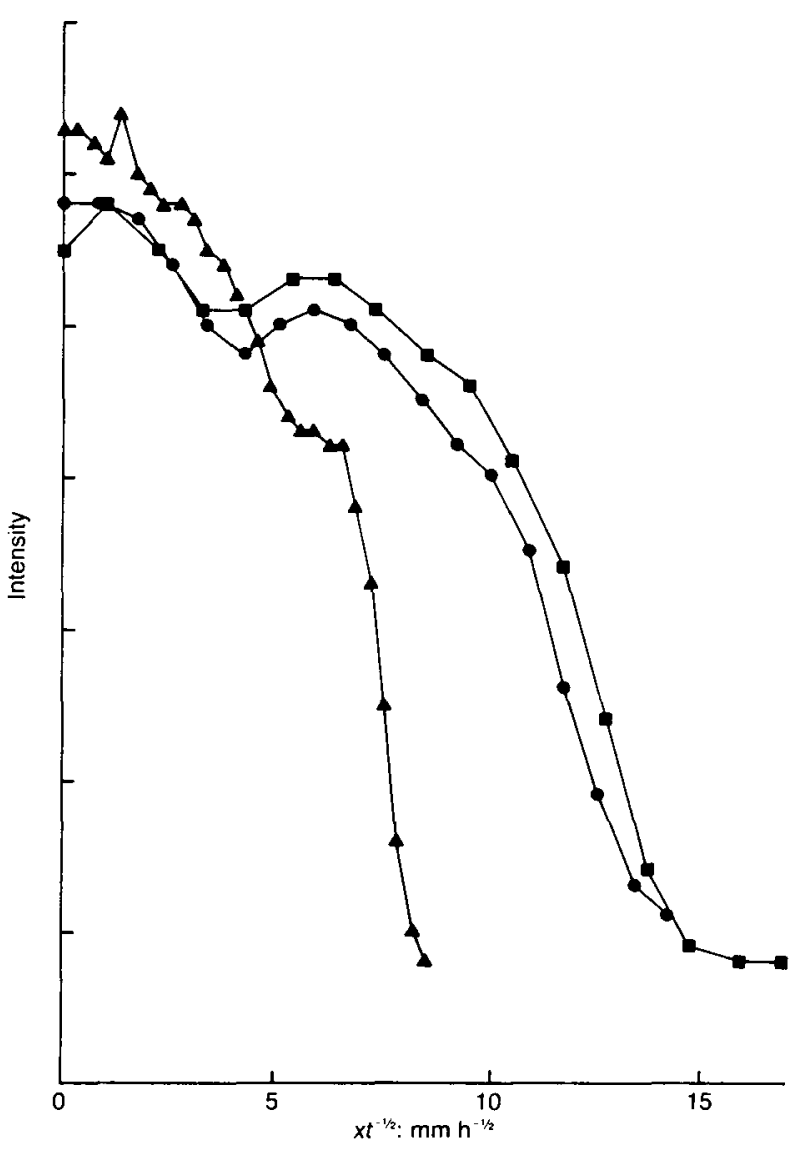

Fig. 2. The profiles of Justnes et al. (Fig. 4) replotted against $x t^{-1 / 2}$ : the capillary suction times are $2.5 \mathrm{~h}$ (squares), $4 h$ (circles) and $24 h$ (triangles)

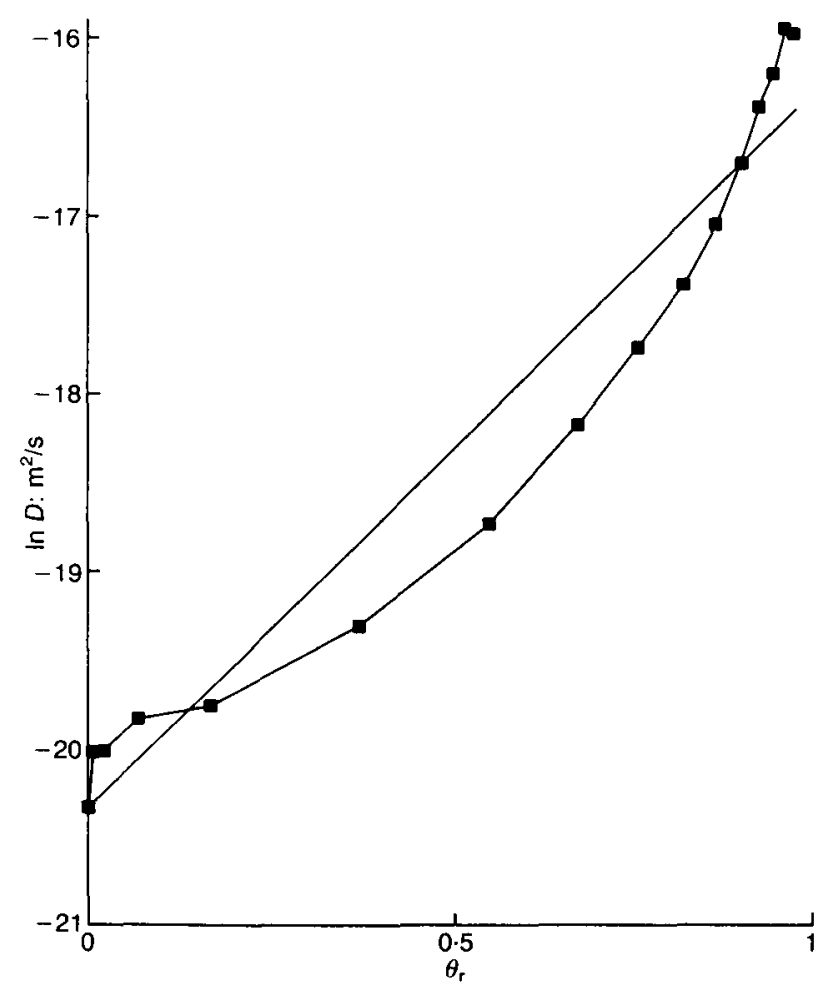

Fig. 3. Graphs showing the hydraulic diffusivity $D(\theta r)$ calculated from the $2.5 \mathrm{~h}$ and $4 \mathrm{~h}$ data of Fig. 2: the straight line has gradient 4.04 


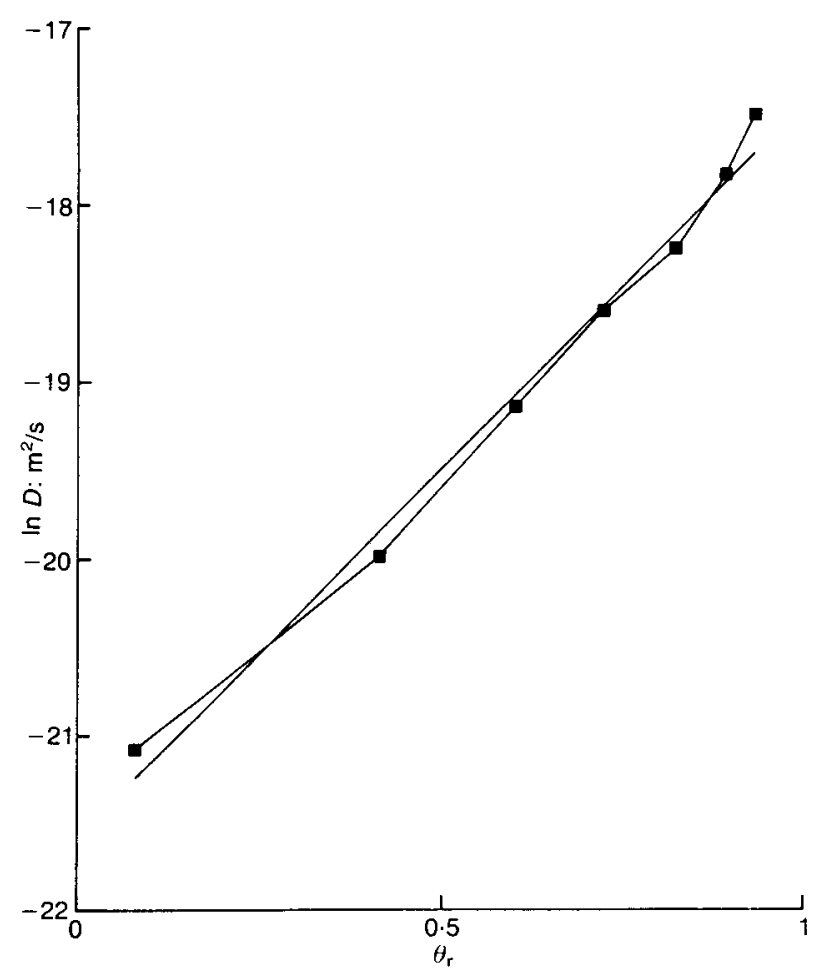

Fig. 4. Graph showing the hydraulic diffusivity $D(\theta r)$ calculated from the $24 \mathrm{~h}$ data of Fig. 2: the straight line has gradient $4 \cdot 142$ applicability of unsaturated flow theory to describe water movement through porous construction materials.

\section{Acknowledgement}

The authors thank the Engineering and Physical Sciences Research Council for financial support.

\section{References}

1. Philip J. R. Theory of infiltration. Adv. Hydrosci., 1965, 5, 215-296.

2. Gummerson R. J. et al. Capillary water transport in masonry structures; building construction applications of Darcy's law. Constr. Pap., 1980, 1, 17-27.

3. GuMmerson R. J. et al. Water transport in porous building materials - II. Hydraulic suction and sorptivity of brick and other masonry materials. Build. Environ., 1981, 15, 101-108.

4. HALL C. The water sorptivity of mortars and concretes: a review. Mag. Concr. Res., 1989, 41, 51-61.

5. GuMmerson R. J. et al. Unsaturated water flow within porous materials observed by NMR imaging. Nature, 1979, 281, 56-57.

6. CARPENTER T. A. et al. Capillary water migration in rock: process and material properties observed by NMR imaging. Mater. Struct., 1993, 26, 286-292.

7. BRUCE R. R. and Klute A. The measurement of water diffusivity. Soil Sci. Soc. Am. Proc., 1956, 20, 458-462.

8. HALL C. Barrier performance of concrete: a review of fluid transport theory. Mater. Struct., 1994, 27, 291-306. 